\title{
BUSINESS PROCESS OUTSOURCING (BPO): UMA ANÁLISE DAS SUAS CARACTERÍSTICAS EM EMPRESAS DE MÉDIO PORTE
}

\author{
Alex Eckert ${ }^{1}$, Lelis Marlon Ribeiro Martins ${ }^{2}$, Roberto Birch Gonçalves ${ }^{3}$ \\ ${ }^{1,2,3}$ Universidade de Caxias do Sul, ${ }^{1}$ PUCRS, ${ }^{3}$ UFRGS \\ ${ }^{1}$ Alex.eckert@bol.com.br \\ ${ }^{2}$ lelismarlon@gmail.com \\ ${ }^{3}$ rbgoncaleucs.br
}

\section{Resumo}

As organizações prestadoras de serviços contábeis têm sido importantes aliadas das pequenas e médias empresas, no entanto precisam apresentar soluções atualizadas aos seus clientes para não se tornarem obsoletas. O uso do Business Process Outsourcing (BPO) contábil e fiscal é demandado pelas empresas como solução estratégica, podendo liberar mais tempo e esforços no seu core business. Diante disso, o presente estudo analisou as características do BPO em empresas de médio porte de Caxias do Sul, sendo para este fim realizada uma pesquisa bibliográfica para identificar as características do BPO, seguido de pesquisa documental para identificar as horas de trabalho e valores pagos ao escritório pelos honorários contábeis. Por fim, foram entrevistados empresários para identificar a percepção dos mesmos quanto às características do BPO. Concluiu-se que a utilização do BPO contábil e fiscal reduziu custos em quatro das cinco empresas estudadas. Ainda assim, a dimensão de custos não é o fator principal de decisão neste nicho de empresas quando optam pela terceirização. As empresas apontaram que o conhecimento dos profissionais, a gestão da atividade e os ganhos em eficiência operacional são de suma importância para os resultados e a satisfação.

Palavras-chave: Business Process Outsourcing. BPO. Custos. Características do BPO. Contabilidade.

\section{BUSINESS PROCESS OUTSOURCING (BPO): ANALYSIS OF FEATURES IN MIDSIZE BRAZILIAN ENTERPRISES}

\section{Abstract}

The organizations providing financial services have been important allies of small and medium enterprises, however needs present updated solutions to its clients not to become obsolete. The use of Business Process Outsourcing accounting and tax is demanded from companies as a strategic solution and can then release more time and efforts on their core business. This paper analyzed the characteristics of BPO in midsize companies in Caxias do Sul, being held for this purpose a literature search to identify the characteristics of BPO, followed by desk research to identify the hours and amounts paid to the office by accounting fees. Finally entrepreneurs were interviewed to identify their perception about BPO characteristics. It was concluded that the use of tax and accounting BPO reduced costs in four of the five companies studied. Yet the scale of costs is no unanimity on this when companies opt for outsourcing niche, considering the 
knowledge of professionals, management of the activity and gains in operational efficiency of paramount importance for the results and the satisfaction of the entrepreneur.

Keywords: Business Process Outsourcing. BPO. Costs. BPO Features. Accounting.

\section{Introdução}

As organizações prestadoras de serviços contábeis têm sido importantes aliadas das pequenas e médias empresas, no entanto o escritório contábil precisa modernizar-se, apresentar soluções alternativas a seus clientes para não tornarem-se obsoletos, pois "o mercado não perdoa aqueles que não conseguem distinguir-se dos demais" (SCHMIDT, 2013, p. 4).

Nesse sentido, Elharidy, Nicholson e Scapens (2013) salientam que há uma tendência crescente para a terceirização das atividades de contabilidade, e que tem sido destacada por diversas organizações públicas e privadas em vários setores. Isto inclui empresas do porte da General Electric (GE), o UK National Health Service, Dresdner Bank, Deutsche Bank, British Telecom, Thomson Holidays, Ford, American Express, HSBC, Citibank, BP, Standard Chartered e a Hewlett Packard, todas estas empresas repassaram a função de contabilidade para provedores de terceiros. (ELHARIDY; NICHOLSON; SCAPENS, 2013).

O Business Process Outsourcing (BPO) contábil e fiscal tem ascensão devido à demanda das empresas que optam pelo serviço como solução estratégica, podendo então focar mais tempo e esforços no seu negócio principal. A ANEFAC (2013) complementa apontando pesquisa interna da PwC (Price Water House Coopers) que 79\% das empresas ainda estão analisando o outsourcing ou não o querem, constituindo apenas $5 \%$ as que utilizam este serviço, mostrando uma possível oportunidade de mercado e a falta de informações das empresas sobre o assunto.

Segundo Byrt (2013), os gastos globais em BPO de finanças e contabilidade ultrapassaram US\$ 25 bilhões em 2013 e crescerão mais 8\% até o ano de 2017, de acordo com pesquisa realizada pelas empresas de serviços KPMG e HFS Research. Alguns fatores que promovem a terceirização são a dificuldade das empresas brasileiras em atender a contabilidade fiscal e sua legislação complexa, além da burocracia. Conforme o site G1, considerando as normas municipais, estaduais e federais, o Brasil tem uma nova regra por hora, sendo assim, o tempo gasto com o cumprimento da legislação fiscal de uma empresa de porte médio é de 2.600 horas ao ano, tempo superior a outros países emergentes $(\mathrm{G} 1,2013)$.

Fabretti (2012) aponta que a legislação tributária constantemente atropela os valores econômicos e, por medidas jurídicas, molda a suas necessidades gerando um novo resultado fiscal, que não mostra a realidade das empresas. Esta constatação abre espaço para a terceirização da atividade contábil em diversos ramos, como fiscal e gerencial. Também se mostra importante o aspecto de custos, pois as "empresas dos mais diversos segmentos contratavam serviços contábeis de terceiros por razões financeiras" (THOMÉ, 2001, p.117). É importante ressaltar também que estas empresas contábeis terceirizadas arcam com elevados custos para manterem-se atualizadas frente à complexa legislação tributária brasileira (ECKERT et al., 2015).

A escolha do tema é motivada pela atual demanda e aumento da complexidade da área contábil nos últimos anos, que suscita o desenvolvimento e a melhora do conhecimento das empresas pelos diversos ramos da contabilidade e sua importância no gerenciamento e tomada de decisões.

Nesse sentido, o objetivo deste estudo foi analisar as características do Business Process Outsourcing contábil e fiscal em empresas de médio porte localizadas na cidade de Caxias do 
Sul, principalmente por entender-se que neste porte de empresa a terceirização pode contribuir fortemente com a liberação da capacidade interna da empresa nas suas práticas de gestão do cotidiano. Para tanto se realizou um estudo de caso num escritório de contabilidade que terceiriza funções para quatro empresas de médio porte de Caxias do Sul, cruzando-se informações obtidas em entrevistas em profundidade com documentos e planilhas com dados referentes aos custos envolvidos ao realizar-se a contabilidade internamente. Cabe ressaltar que, de acordo com a Fundação de Economia e Estatística do estado do Rio Grande do Sul - FEE (2014), a cidade de Caxias do Sul participa com 6,3\% do Produto Interno Bruto (PIB) estadual, justificando-se, assim, a realização do presente estudo com empresas estabelecidas na referida cidade.

\section{Referencial Teórico}

As empresas de serviços contábeis têm evoluído a partir da fusão de empresas de contabilidade, da compra das carteiras de clientes e da associação de contadores. Por vezes o contador passou a ser empresário sendo substituído, no dia a dia, por mão de obra contratada ampliando sua capacidade de oferecer serviços. Sendo assim, os honorários evoluíram de valores para cobrir despesas para se transformar na principal receita de uma organização contábil (THOMÉ, 2001). Nesse sentido, o CFC (2013) observa que desde 2004 nota-se um crescimento constante das organizações contábeis no Brasil, tanto em sociedades como o surgimento de empresários individuais. Diante desta evolução, para evitar a obsolescência, é preciso diversificação na contabilidade, conforme explica Schmidt (2013, p. 4): "hoje, é uma profissão mais estratégica, embora também mais complexa. Seguindo essa lógica, as organizações contábeis também precisam acompanhar os novos contextos do setor para serem bem-sucedidas". Uma possibilidade de diversificação e modernização encontra-se na terceirização ou outsourcing.

\subsection{Outsourcing}

O outsourcing, conhecido no Brasil como terceirização, é uma forma das empresas realizarem parte do seu negócio através de terceiros. Moraes, Silveira e Saratt (2003) classificam a terceirização em duas formas: externa, que foi a pioneira, onde os prestadores não estão em contato físico com o tomador. E interna, quando o trabalho é conjunto e realizado na sede da empresa.

A terceirização faz parte de uma renovação que as empresas brasileiras passaram e continuam passando. Seja no que diz respeito a sua atividade principal como também nos serviços adjuntos como a contabilidade e seus ramos. No Brasil já se via indícios de uso da terceirização pela década de 50, que serviu para inovar e alavancar novas atividades, além de contribuir para o desenvolvimento do país (ALVAREZ, 1998; LACITY; WILLCOCKS, 2014). O trabalho terceirizado está de acordo com a legislação vigente, conforme parágrafo único do art. 170 da constituição federal combinado com o art. 594 do código civil, onde se ressalta que "Toda a espécie de serviço ou trabalho lícito, material ou imaterial, pode ser contratada mediante retribuição." (CÓDIGO CIVIL, 2002).

De acordo com Thomé (2001, p.117), "quando surgiu o termo terceirização, as empresas contábeis já praticavam a atividade hoje definida como prestação de serviços terceirizados", muito em conta da demanda das pequenas e médias empresas. São nestas empresas que, segundo Rocco (2013) o custo da contabilidade terceirizada é menor se comparada à implantação de departamento contábil, fiscal e pessoal internamente. Entre os motivos desta afirmação estariam à 
falta de conhecimento técnico e o espaço físico. Além disso, depois da implantação do padrão IFRS a complexidade da contabilidade e suas obrigações contribuíram para justificar os benefícios da terceirização ANEFAC (2013).

Em estudo feito sobre a viabilidade técnica e econômica da terceirização dos serviços contábeis, Mattos, Dias e Gonçalves (2008) descrevem que os principais motivos da terceirização da contabilidade são a agilidade das decisões, maior lucratividade e crescimento, redução de desperdício e aumento de qualidade. O estudo mostra que $86 \%$ das empresas consideram a contabilidade terceirizada relevante para o desempenho industrial. Ainda caracteriza os pontos positivos da terceirização, como o acréscimo de qualidade, competitividade, agilidade na tomada de decisão e redução de custos. E seus pontos negativos, como a ineficiência nas informações geradas, a retirada de documentos da empresa, a falta de comprometimento, a não exclusividade e o custo de demissões (MATTOS; DIAS; GONÇALVES, 2008)

Para ANEFAC (2013) o ponto principal analisado pelas empresas na decisão de terceirizar é a necessidade de pessoas trabalhando ao lado dos gestores, pois a terceirização acontece em sua grande maioria nos escritórios. Moraes, Silveira e Saratt (2003) caracterizam o outsourcing em diversos objetos: i) Terceirização de serviços; ii) Terceirização de serviços e materiais; iii) Terceirização de serviços e equipamentos; iv) Terceirização plena.

A terceirização plena faz parte da nova era da terceirização onde há execução, gestão e resultados compartilhados pelo prestador (MORAES; SILVEIRA; SARATT, 2003). Esta nova era visualiza-se no meio acadêmico, caracterizada pelo conceito business process outsourcing.

\subsection{Business Process Outsourcing(BPO)}

Segundo Halvey e Melby (2007), o BPO começou como a delegação de processos para servidores de TI que gerenciavam e administravam com maior conhecimento determinado negócio, mas se difundiu em diversas áreas devido o surgimento de oportunidades. Click e Duening (2005) conceituam O BPO como a mudança de serviços para um prestador externo, podendo ser prestado internamente, externamente ou até fora do país a partir do momento que se torna confiável. Deve envolver soluções técnicas e sociais da organização, pois para ser eficaz necessita de diversos fatores encontrados em uma equipe e não apenas em uma pessoa.

Para Elharidy, Nicholson e Scapens (2013), o BPO é a transferência de responsabilidade na execução de um processo de negócio que é normalmente realizado na empresa, entretanto, não relacionado à sua atividade fim. Assim é a contratação de um prestador expert em serviços contábeis, para fornecer serviços que não o core business da empresa (FIGUEIREDO; BREMER; MALDONADO, 2003). Porém esses autores tem posição contrária a Yang et al. (2006), que descrevem o BPO como uma terceirização onde o prestador de serviço administra e gerencia qualquer atividade.

Yang et al. (2006) afirmam que BPO é um termo consolidado, porém em constante mudança devido as novas tecnologias e crescente demanda. Em complemento, Sîrbu, Nag e Pintea (2012) caracterizam BPO com a finalidade de redução de custos, acréscimo de qualidade, ganhos de facilidades fiscais, obtenção de benefícios da gestão de risco ou de especialização operacional. Entretanto Vora (2010) afirma que pontos negativos como a perda do controle e a queda de rendimento foram identificados por algumas empresas que fizeram tratativas de BPO e não tiveram novas intenções de retorno. Ainda assim, Vora (2010) admite que o BPO seja o melhor caminho se a empresa verificar além dos melhores preços, os reflexos do contrato e as fases do serviço. 
Segundo Byrt (2013), o BPO de finanças e contabilidade não deve ser visto como um substituto à contabilidade das empresas e sim como uma extensão. Na área fiscal e de auditoria, as empresas contam com a gestão pelos escritórios externos devido a constantes mudanças e complexidade (HALVEY; MELBY, 2007). Assim, as organizações que oferecem este serviço devem ir além do conhecimento dos procedimentos da área, necessitam compreenderem detalhadamente as operações dos clientes, possuir habilidade com o software ERP e ter capacidade de atender aos padrões IFRS (HERNANDES, 2010). De fato, Lima (2009) alega que o BPO traz maior segurança em atividades não usuais a do tomador do serviço, permitindo maior foco e concentração no seu core business, originando economias tributárias, valoração da empresa e facilidade no cumprimento de objetivos. Nessa linha, Hernandes (2010) descreve que os principais motivos da procura do BPO são a redução de custos, maior eficiência operacional e especialização constante do prestador.

A partir do exposto até aqui e para esse estudo, considerou-se que a definição que fornece a melhor abrangência da BPO é: "a terceirização plena interna ou externa (MORAES; SILVEIRA; SARATT, 2003), de uma atividade que não o core business do cliente (ELHARIDY; NICHOLSON; SCAPENS, 2013) com administração e total gestão por uma equipe terceirizada, que pode ser nacional ou internacional (CLICK; DUENING, 2005) com base na tecnologia (HALVEY; MELBY, 2007)".

\section{Procedimentos metodológicos}

A metodologia de pesquisa esclarece questões tanto dos objetivos propostos quanto para o próprio processo de pesquisa. Segundo Strauss e Corbin (1998), metodologia é um conjugado de fórmulas e artifícios utilizados para a arrecadação e analise de informações. $O$ método aprovisiona o necessário para o alcance do objetivo proposto. Assim, a presente pesquisa é, quanto à natureza aplicada, pois trata de gerar conhecimentos diante da aplicação prática, dirigidos à solução de problemas concretos. Quanto aos objetivos propostos, é uma pesquisa de cunho exploratório. Segundo Gil (2007), esse tipo de pesquisa visa identificar os fatores que levam a ocorrência do fenômeno e absorve tanto pesquisas bibliográficas como estudos de casos.

Assim, quanto aos procedimentos técnicos, à pesquisa abrange revisão bibliográfica, documental, aprofundamento do caso com entrevistas em profundidade apoiada por roteiro semiestruturado com os representantes das empresas escolhidas. A revisão bibliográfica apoiou o entendimento dos construtos teóricos, nas entrevistas em profundidade buscou-se captar as percepções identificadas, as quais foram agrupadas em oito dimensões do BPO referenciadas: custos, qualidade, resultado, administração, conhecimento, tomada de decisões, confiabilidade, comprometimento e tributação. As dimensões estão representadas do Quadro 1.

Como forma de apoio as entrevistas em profundidade utilizou-se de um roteiro semiestruturado conforme sugerido por Bardin (2005) para desenvolver e entender as oito categorias da pesquisa. As entrevistas foram realizadas nos meses de janeiro a maio de 2014, tiveram a duração média de 40 minutos, sendo posteriormente transcritas para facilitar a análise das categorias propostas.

No Quadro 1, a coluna “dimensão" se refere a cada uma das oito categorias de análise, a coluna da métrica mostra a pergunta que orientou o entrevistador para compreender a percepção dos entrevistados quanto a dimensão do BPO e na coluna de autor estão descritos os autores que, segundo a revisão bibliográfica, que fornecem sustentação teórica a cada uma das dimensões. 
Quadro 1 - Dimensões e métricas

\begin{tabular}{|c|c|c|}
\hline Dimensão & Métrica & Autor \\
\hline \multirow{2}{*}{ Custos } & $\begin{array}{l}\text { Você considera a terceirização de serviços de contabilidade como uma } \\
\text { forma de redução de despesas? }\end{array}$ & \multirow[t]{2}{*}{ Rocco (2013) } \\
\hline & $\begin{array}{l}\text { É importante para você reduzir estruturas e controle sobre atividades } \\
\text { que não a atividade fim da empresa? }\end{array}$ & \\
\hline \multirow{3}{*}{ Qualidade } & $\begin{array}{l}\text { Em que nível de satisfação você se encontra com o serviço contábil } \\
\text { prestado na sua empresa? }\end{array}$ & \multirow[t]{2}{*}{ Hernandes (2010) } \\
\hline & $\begin{array}{l}\text { O que falta para o serviço contábil atenda plenamente suas } \\
\text { expectativas? }\end{array}$ & \\
\hline & $\begin{array}{l}\text { A perda do controle ou queda de rendimento é relevante na decisão de } \\
\text { terceirizar ou internalizar o serviço contábil? }\end{array}$ & Vora (2010) \\
\hline \multirow{2}{*}{ Resultado } & $\begin{array}{l}\text { Você acredita que a terceirização do serviço contábil the da maior } \\
\text { eficiência operacional? }\end{array}$ & Hernandes (2010) \\
\hline & $\begin{array}{l}\text { Quais ganhos ou perdas acredita que empresa e organização contábil } \\
\text { alcançam conjuntamente com a terceirização plena? }\end{array}$ & Lima (2009) \\
\hline \multirow[t]{2}{*}{ Administração } & $\begin{array}{l}\text { Você acredita que a transferência de responsabilidade do serviço } \\
\text { contábil lhe permite um maior foco no seu core business? }\end{array}$ & $\begin{array}{l}\text { Elharidy, } \\
\text { Nicholson } \\
\text { Scapens }(2013)\end{array}$ \\
\hline & $\begin{array}{l}\text { Você considera importante a gestão de riscos e administração total da } \\
\text { atividade por parte do escritório? }\end{array}$ & Lima (2009) \\
\hline Conhecimento & $\begin{array}{l}\text { Você se sente mais confortável com a terceirização do serviço contábil } \\
\text { no que diz respeito à especialização e preparo dos profissionais e do } \\
\text { escritório como um todo neste ramo de atividade? }\end{array}$ & Hernandes (2010) \\
\hline \multirow{3}{*}{$\begin{array}{l}\text { Confiabilidade } \\
\text { e comprometi- } \\
\text { mento }\end{array}$} & $\begin{array}{l}\text { Confia que os resultados e as demonstrações apresentadas pela } \\
\text { contabilidade são de total credibilidade? }\end{array}$ & Lima (2009) \\
\hline & $\begin{array}{l}\text { Quais suas considerações sobre o comprometimento dos profissionais } \\
\text { terceirizados com os objetivos da empresa e com a qualidade dos } \\
\text { serviços prestados? E com a não exclusividade? }\end{array}$ & $\begin{array}{l}\text { Mattos, Dias e } \\
\text { Gonçalves (2008) }\end{array}$ \\
\hline & $\begin{array}{l}\text { Você sente mais confiança e transparência com o serviço de } \\
\text { profissionais contábeis que visitam a empresa? }\end{array}$ & Lima (2009) \\
\hline \multirow{2}{*}{$\begin{array}{l}\text { Tomada de } \\
\text { decisões }\end{array}$} & $\begin{array}{l}\text { As informações advindas do serviço contábil são consideradas nos } \\
\text { processos de tomada de decisões? Como? }\end{array}$ & $\begin{array}{l}\text { Mattos, Dias e } \\
\text { Gonçalves (2008) }\end{array}$ \\
\hline & $\begin{array}{l}\text { Com que periodicidade o contador e o administrador se reúnem para } \\
\text { discutirem assuntos pertinentes à administração da empresa? }\end{array}$ & $\begin{array}{l}\text { Mattos, Dias e } \\
\text { Gonçalves (2008) }\end{array}$ \\
\hline Tributação & $\begin{array}{l}\text { Você percebe economia tributaria no momento da terceirização de } \\
\text { profissionais? }\end{array}$ & Lima (2009) \\
\hline
\end{tabular}




\begin{tabular}{|l|l|l|}
\hline $\begin{array}{l}\text { Você considera relevante o custo de demissões no momento em que } \\
\text { opta pela terceirização? }\end{array}$ & $\begin{array}{l}\text { Mattos, Dias e } \\
\text { Gonçalves (2008) }\end{array}$ \\
\hline
\end{tabular}

Fonte: Autores

Além das entrevistas utilizou-se a análise documental como instrumento para triangulação dos dados de pesquisa. Essa análise foi executada em duas partes simultâneas e complementares. $\mathrm{Na}$ primeira parte se utilizou do roteiro semiestruturado para conduzir as entrevistas em profundidade, para a posterior a análise de conteúdo (BARDIN, 2004) para depreender-se a opinião dos entrevistados quanto: i) Medir o nível de satisfação dos clientes com o serviço prestado; ii) Identificar a percepção do cliente sobre o BPO contábil e fiscal.

$\mathrm{Na}$ segunda parte foram analisadas as planilhas de produção dos funcionários extraídas a partir de controles internos do escritório contábil estudado, com base nos anos de 2012 e 2013. Investigou-se, de modo comparativo, os custos e despesas antes e após a implementação do BPO contábil e fiscal através do software Microsoft Excel.

\subsection{Caracterização do ambiente de pesquisa}

As empresas utilizadas para análise dos dados neste trabalho foram expostas com nomes fictícios preservando-se a privacidade, o perfil das empresas é apresentado no Quadro 2. Selecionaram-se cinco empresas distintas de médio porte, para realizar as entrevistas em profundidade de cada dimensão do BPO detectada e seus aspectos em cada uma delas.

Quadro 2 - Perfil das empresas estudadas

\begin{tabular}{|l|l|c|l|l|}
\hline Empresa & Tributação / Lucro & Funcionários & Tipo & Ramo \\
\hline Empresa A & Real & 85 & Indústria & Autopeças \\
\hline Empresa B & Real & 60 & Indústria & Utensílios domésticos \\
\hline Empresa C & Presumido & 118 & Comercio & Vestuário e calçados \\
\hline Empresa D & Presumido & 117 & Indústria & Autopeças \\
\hline Empresa E & Presumido & 119 & Comércio & Vestuário e calçados \\
\hline
\end{tabular}

O Quadro 4 mostra o perfil dos entrevistados. O cargo é a posição que o entrevistado ocupa atualmente na empresa pesquisada, a formação é sua titulação acadêmica, o nível de conhecimento sobre a metodologia BPO foi atribuído deduzindo-se dos dados da entrevista e o tempo de empresa é o período em que o entrevistado está exercendo atividade na empresa.

Quadro 3 - Perfil dos entrevistados

\begin{tabular}{|l|l|l|l|l|}
\hline Entrevistado & Cargo & Formação & $\begin{array}{l}\text { Nível de } \\
\text { conhecimento }\end{array}$ & $\begin{array}{l}\text { Tempo de } \\
\text { empresa }\end{array}$ \\
\hline E 1; Empresa A & Administrador & Administração de empresas & Regular & 21 anos \\
\hline E 2; Empresa B & Gerente Financeiro & Técnico em contabilidade & Aprofundado & 2 Anos \\
\hline E 3; Empresa C & Administrador & Administração de empresas & Básico & 18 anos \\
\hline E 4; Empresa D & Gerente/Unidade & Administração de empresa & Aprofundado & 19 anos \\
\hline E 5; Empresa E & Diretor & Administração de empresas & Básico & 15 anos \\
\hline
\end{tabular}


Pode-se notar que os entrevistados têm, em média, bom tempo de empresa e atuam em posição de alta gestão, esses fatos qualificam as respostas dadas.

\section{Análise dos Dados e Discussão dos Resultados}

O BPO contábil e fiscal é a terceirização plena do serviço munido da gestão e de tecnologia. Este serviço tem uma série de dimensões abrangidas, como o custo, a qualidade, a administração, o conhecimento, a confiabilidade, o comprometimento, a tomada de decisões e a tributação (QUADRO 1).

Notou-se a preferência dos entrevistados pelo BPO interno como melhor forma de serviço contábil. Entre os fatores que definiram a preferência, destacam-se a viabilidade econômica, eficiência operacional, a comunicação entre profissionais e a agilidade dos resultados. Entre os 5 entrevistados, apenas E4 repensa o modelo, todavia seu descontentamento atual é causado por fatores como a falta de integração entre os softwares empresarial e contábil e a carência de escritórios capazes de desenvolver o BPO de forma capacitada. A percepção do E4 coincide com a abordagem de Rezende (2011) quanto aos controles internos e sugere a utilização de um sistema de informação único para maximizar os resultados do BPO. Atingem-se a partir dessa ação as necessidades dos clientes quanta agilidade dos resultados e a comunicação solicitada, visando acréscimo da satisfação das empresas. Em complemento, aperfeiçoar o processo de trabalho, quanto ao conhecimento das operações do cliente e a capacitação com seu ERP (HERNANDES, 2010) é valido para o alcance desse objetivo. Para a análise de custos nessa pesquisa, confrontaram-se os honorários do trabalho terceirizado com o valor do salário dos profissionais necessários para cumprir a atividade. A Tabela 1 demonstra o salário médio dos profissionais da área nos anos estudados.

Tabela 1 - Salários médios no Brasil

\begin{tabular}{l|l|l|l|l}
\hline \multicolumn{1}{c|}{ Cargo } & \multicolumn{1}{c|}{$\begin{array}{c}\text { Porte da } \\
\text { empresa }\end{array}$} & $\begin{array}{c}\text { Salário médio } \\
2012\end{array}$ & \multicolumn{1}{c}{ Salário médio } & $\begin{array}{c}\text { Salário médio } \\
2014\end{array}$ \\
\hline Controller & Médio & $\mathrm{R} \$ 15.000,00$ & $\mathrm{R} \$ 16.000,00$ & $\mathrm{R} \$ 16.500,00$ \\
\hline Contador (Coordenador) & Médio & $\mathrm{R} \$ 6.750,00$ & $\mathrm{R} \$ 7.500,00$ & $\mathrm{R} \$ 8.000,00$ \\
\hline Analista Contábil/Fiscal Pleno & Médio & $\mathrm{R} \$ 3.750,00$ & $\mathrm{R} \$ 3.750,00$ & $\mathrm{R} \$ 4.000,00$ \\
Analista Contábil/Fiscal Junior & Médio & $\mathrm{R} \$ 2250,00$ & $\mathrm{R} \$ 2.500,00$ & $\mathrm{R} \$ 2500,00$ \\
\hline
\end{tabular}

Fonte: Adaptado de Half (2014).

As análises dos dados de custo auxiliaram na identificação do melhor modelo de serviço contábil. Apenas a empresa D apresentou valores significativos de vantagem com a internalização de profissionais.

Os salários expostos na Tabela 1 foram extraídos do guia salarial de Half (2014) empresa especializada em recrutamento de profissionais da área financeira, com mais de 60 anos de experiência. Para a capacidade produtiva considerou-se o tempo definido na legislação federal brasileira com duração do trabalho normal não superior a oito horas diárias e quarenta e quatro semanais. 
Quanto à percepção sobre custos, os entrevistados 1 e 2 acreditam que a redução de custos para a empresa é o principal motivo para a terceirização da contabilidade.

Segundo E1, "há complexidade em nossas operações, seria caro e inseguro elaborar contabilidade interna aqui". Analisando sua planilha de produção contábil, conforme Tabela 2, percebeu-se que, embora as horas de trabalho tenham sido reduzidas, o honorário aumentou e se manteve em 2014 proporcionalmente aos meses já ocorridos.

Tabela 2 - Planilha de produção contábil - Empresa A

\begin{tabular}{l|l|l|l}
\hline \multicolumn{1}{c|}{ Empresa A } & \multicolumn{1}{|c|}{$\mathbf{2 0 1 2}$} & \multicolumn{1}{c}{$\mathbf{2 0 1 3}$} & \multicolumn{1}{c}{$\mathbf{2 0 1 4}$} \\
\hline Total de horas & $3204: 42: 21$ & $1789: 11: 12$ & $742: 31: 51$ \\
\hline Total de honorários & R\$ 45.500,00 & R\$ 69.550,00 & R\$ 26.750,00 \\
\hline Tipo terceirização & Externa & Externa & Interna \\
\hline
\end{tabular}

Conforme o E2 é inviável hoje manter um contador na empresa, que faça todo o serviço contábil e fiscal. Segundo ele "tem-se uma redução de custos de 50\% com a terceirização". Justifica este calculo com a percepção de que, "mantendo um contador aqui na empresa tem toda parte de impostos que incidem em cima do salário" (E2).

Analisando sua planilha de produção, conforme Tabela 3, visualiza-se uma redução de 235\% no total de horas trabalhadas de 2013 ante 2012. Reduziu-se R\$ 19.500,00 de honorários com a troca de forma de trabalho, para a terceirização interna.

Tabela 3 - Planilha de produção contábil - Empresa B

\begin{tabular}{l|c|c|c}
\hline \multicolumn{1}{c}{ Empresa B } & $\mathbf{2 0 1 2}$ & $\mathbf{2 0 1 3}$ & $\mathbf{2 0 1 4}$ \\
\hline Total de horas & $2203: 11: 54$ & $657: 06: 47$ & $132: 20: 45$ \\
\hline Total de honorários & $\mathrm{R} \$ 71.500,00$ & $\mathrm{R} \$ 52.000,00$ & $\mathrm{R} \$ 24.000,00$ \\
\hline Tipo terceirização & Externa & Interna & Interna \\
\hline
\end{tabular}

Na empresa B percebe-se que após a internalização, as horas de trabalho reduziram significativamente nos dois anos subsequentes. O indicador positivo encontra-se no ano de 2014, onde a empresa apresenta economia com o BPO de R\$44.000,00. Concluiu-se ao fim da análise que a percepção de E2 sobre a redução de valores com a terceirização está correta, sendo ainda maior que os $50 \%$ explanados.

E3 percebe uma vantagem na contabilidade terceirizada, porém enfatiza, "Não é o principal". Segundo ele, para o tamanho atual da empresa montar uma equipe de trabalho não se justificaria economicamente. Em análise da Tabela 4, verifica-se uma redução de 582\% nas horas trabalhadas de 2012 para 2013. 
Tabela 4 - Planilha de produção contábil - Empresa C

\begin{tabular}{l|c|c|c}
\hline \multicolumn{1}{c|}{ Empresa C } & $\mathbf{2 0 1 2}$ & $\mathbf{2 0 1 3}$ & $\mathbf{2 0 1 4}$ \\
\hline Total de horas & $3656: 17: 01$ & $536: 01: 52$ & $328: 38: 07$ \\
\hline Total de honorários & R\$ 84.500,00 & R\$ 84.500,00 & R\$ 32.500,00 \\
\hline Tipo terceirização & Interna & Interna & Interna \\
\hline
\end{tabular}

Conforme o entrevistado 4, os custos com a atividade contábil são o segundo aspecto em nível de importância no momento da opção pela terceirização da atividade:

"devido ao tamanho da empresa que tínhamos, não havia estrutura física e financeira para internalizar todos os profissionais necessários, hoje a empresa encontra-se em um momento diferente e repensa o modelo, pois já existe o entendimento de que as coisas podem andar melhor se fosse feito internamente" (E4).

Analisando sua planilha de produção, na Tabela 5, percebe-se que os honorários se mantiveram ao longo dos anos.

Tabela 5 - Planilha de produção contábil - Empresa D

\begin{tabular}{l|c|c|c}
\hline \multicolumn{1}{c|}{ Empresa D } & $\mathbf{2 0 1 2}$ & $\mathbf{2 0 1 3}$ & $\mathbf{2 0 1 4}$ \\
\hline Total de horas & $4147: 09: 14$ & $2088: 12: 58$ & $741: 03: 51$ \\
\hline Total de honorários & R\$ $143.000,00$ & R\$ $143.000,00$ & R \$ 55.000,00 \\
\hline Tipo terceirização & Interna & Interna & Dpto Interno + T.externa \\
\hline
\end{tabular}

Em 2013 com a redução de praticamente 99\% nas horas trabalhadas, um contador suportaria todo o trabalho, tendo a empresa um custo de $\mathrm{R} \$ 90.000,00$, a economia com departamentos internos seria de $\mathrm{R} \$ 53.000,00$.

O entrevistado 5 não considera os custos como principal dimensão na decisão pela terceirização:

"Custo é um dos aspectos, mas não necessariamente tem-se uma redução de custos na terceirização. O que se tem é uma melhor qualidade do serviço pelas equipes multidisciplinares, se eu optasse por ter a contabilidade interna hoje eu teria que me envolver muito mais diretamente com o gerenciamento da parte contábil, fiscal e de departamento de pessoal" (E5).

E5 enfatizou que o contrato de trabalho terceirizado pode ser oneroso para a empresa. Analisando sua planilha de produção, conforme Tabela 6, constatou-se que os honorários se mantiveram e que a empresa, entre as organizações estudadas foi a que menos apresentou redução de horas de trabalho de 2012 para 2013. Unido a isto, seu valor de honorários se manteve nos três anos. 
Tabela 6 - Planilha de produção contábil - Empresa E

\begin{tabular}{l|c|c|c}
\hline \multicolumn{1}{c|}{ Empresa E } & $\mathbf{2 0 1 2}$ & $\mathbf{2 0 1 3}$ & $\mathbf{2 0 1 4}$ \\
\hline Total de horas & $524: 12: 29$ & $476: 00: 25$ & $319: 28: 49$ \\
\hline Total de honorários & R\$ 84.500,00 & R\$ 84.500,00 & R\$ 39.000,00 \\
\hline Tipo terceirização & Interna & Interna & Interna \\
\hline
\end{tabular}

Observou-se que nos três anos a empresa necessitaria de um contador para suprir a demanda, com valores de $\mathrm{R} \$$ 81.000,00, $\mathrm{R} \$ 90.000,00$ e $\mathrm{R} \$ 96.000,00$ em 2012, 2013 e na proporção estabelecida de 2014, respectivamente. Sendo assim a terceirização não seria vantajosa em 2012 por R\$ 3.500,00, confirmando a citação de E5 sobre a possibilidade de desvantagem do BPO em relação a custos. Contudo a terceirização se tornou vantajosa por R \$5.500,00 em 2013 e R\$ 11.500,00 em 2014. Percebeu-se que, com a combinação de departamento interno e BPO externo em 2014, as horas apresentaram uma redução, que se for sustentada ao longo do ano, ira gerar ganhos ainda maiores. Embora a empresa $E$ tenha apresentado vantagem em internalizar em 2012, o BPO gerou vantagem nos anos subsequentes.

Identificou-se que a troca da terceirização externa para interna, apesar de não apresentar ganhos de forma muito clara na empresa A, reduziu horas e honorários na empresa $\mathrm{B}$, nos anos de 2013 e 2014. Mesmo que todas as empresas tenham exibido redução de horas, por causa dos avanços tecnológicos, a empresa $\mathrm{B}$ conciliou os decréscimos de horas com a redução dos valores de honorários, mostrando a eficiência operacional gerada pelo BPO interno perante o externo. Destaca-se que as simulações abrangeram exclusivamente os valores de salários dos profissionais, excetuando possíveis importâncias tributárias, gastos de estrutura, compra de software, investimento em especializações para profissionais da área e até montagem do departamento com coordenadores por área.

Concluiu-se que o BPO contábil e fiscal reduz custos em médias empresas, pois nesse trabalho, quatro das cinco empresas apresentaram economia com a terceirização, resultado que corroborou Rocco (2013) quanto à redução de custos na terceirização em PMEs. A Tabela 7 mostra as economias geradas pelas empresas através do BPO.

Tabela 7 - Economia do BPO contábil e fiscal

\begin{tabular}{|c|c|c|c|}
\hline Empresa & 2012 & 2013 & 2014 \\
\hline Empresa A & * $137 \%$ mais econômico & *29\% mais econômico & *38\% mais econômico \\
\hline Empresa B & *51\% mais econômico & *73\% mais econômico & *85\% mais econômico \\
\hline Empresa C & *28\% mais econômico & *6\% mais econômico & *14\% mais econômico \\
\hline Empresa D & $5 \%$ mais oneroso & $37 \%$ mais oneroso & $33 \%$ mais oneroso \\
\hline Empresa E & 4\% mais oneroso & *6\% mais econômico & *14\% mais econômico \\
\hline
\end{tabular}

Os percentuais da Tabela 7 foram calculados através dos valores identificados nas planilhas de produção, confrontados com a possibilidade de internalização. Os valores marcados com asterisco mostram os locais de maior economia com o BPO, enquanto os resultados marcados em negrito mostram onde o BPO se mostrou mais oneroso para a empresa.

A empresa D foi singular e apresentou resultados negativos com a terceirização nos três anos estudados, de acordo com a percepção de seu empresário. Um dos motivos para o resultado da empresa D é o fator de ser a única das indústrias estudadas que não possui ERP que abranja a 
contabilidade, sendo a operação realizada no software contábil. Ressalva-se, contudo que a vantagem percebida na implantação de contabilidade interna ao invés do BPO limita-se aos custos, prevendo-se elevação dos mesmos, caso o empresário opte pelo investimento em ampliar o conhecimento, ponto positivo destacado por E4 na avaliação do BPO contábil e fiscal.

Percebeu-se que as empresas A e B apresentaram as maiores economias com a terceirização, sendo as empresas onde os entrevistados classificaram a dimensão de custos como o aspecto mais importante do BPO.

Quanto à percepção dos clientes sobre as dimensões identificadas no BPO contábil e fiscal, Identificou-se como principal dimensão nas empresas A e B o custo da terceirização, já na empresa $\mathrm{C}$ e $\mathrm{D}$, o conhecimento e a capacidade técnica dos profissionais disponibilizados sobre a operação como o aspecto mais relevante. Para a empresa E, a gestão da atividade pelo parceiro é fundamental para a escolha do serviço terceirizado, os resultados corroboram com Sîrbu, Nag e Pintea (2012). Além disso, a redução de custos tem relevância, mas não é a maior preocupação das empresas analisadas.

Sobre os pontos negativos do BPO destacados por Mattos, Dias e Gonçalves (2008), houve compartilhamento pelos entrevistados apontando a ineficiência nas informações geradas e a retirada de documentos da empresa, embora o custo de demissões tenha sido percebido apenas por E2.

Quanto à satisfação dos clientes com o serviço prestado, a entrevista constatou que o entrevista E1 está satisfeito com o BPO, entretanto para atender plenamente suas expectativas deseja redução de honorários. Já E2 está satisfeito, mas deseja maior agilidade nas atividades prestadas e em seus resultados. E3 está muito satisfeito com o serviço, devido principalmente a credibilidade do prestador, que preza pela manutenção das atividades e o esforço em mantê-las em dia. $\quad$ E4, por sua vez, manifestou o único parecer negativo sobre a satisfação do trabalho, pois está encontra-se muito insatisfeito com o BPO contábil e fiscal. Os fatores apontados foram a falta de integração entre os sistemas, a falta de qualidade das informações e a falta de comunicação entre os profissionais. Sua percepção está de acordo com Hernandes (2010) no que diz respeito aos profissionais terceirizados necessitarem de familiarização com as operações do cliente e possuir habilidade em suas ferramentas.

Já E5 está satisfeito com o serviço, embora aponte a necessidade de melhor comunicação e integração entre os profissionais terceirizados e colaboradores para atender plenamente.

Para identificar novos fatores, com intuito de melhorar a forma de trabalho na região estudada, adicionaram-se ao roteiro de entrevista perguntas de cunho exploratório. Nesse sentido, de acordo com o Quadro 4 as seguintes sugestões foram apresentadas.

\section{Quadro 4 - Novos fatores}

\begin{tabular}{|c|l|l|}
\hline ID & \multicolumn{1}{|c|}{ Sugestão } & \multicolumn{1}{c|}{ Análise } \\
\hline E1 & $\begin{array}{l}\text { Solucionar } \\
\text { problemas inclusive } \\
\text { do ERP do cliente }\end{array}$ & $\begin{array}{l}\text { Abre-se uma oportunidade de parceria entre o escritório prestador do BPO e } \\
\text { empresas de ERP, com o escritório como um intermediador de implantação } \\
\text { e manutenção. }\end{array}$ \\
\hline E2 & $\begin{array}{l}\text { Soluções de direito } \\
\text { trabalhista e } \\
\text { tributário }\end{array}$ & $\begin{array}{l}\text { Embora não seja o foco do escritório, é interessante também o sistema de } \\
\text { indicação e parceria, pois a empresa tem confiança no prestador de serviço } \\
\text { contábil. }\end{array}$ \\
\hline E4 & Gestor de contas & $\begin{array}{l}\text { Ter um profissional especializado com conhecimento tanto contábil quanto } \\
\text { fiscal para prestar contas à empresa. Colaboradores com especializações em } \\
\text { ramos específicos poderiam agregar valor principalmente no processo de } \\
\text { tomada de decisões. }\end{array}$ \\
\hline
\end{tabular}


Percebeu-se, também, que fatores como a comunicação entre os profissionais é algo extremamente importante no BPO, argumento citado por E3, E4 e E5. Identificou-se que estas empresas tem a contabilidade em sistema de software contábil e não em ERP próprio, o que agravou o problema.

Identificou-se que as empresas A e B são dependentes das informações advindas do BPO para a tomada de decisão, o fato de as duas possuírem integração das informações via ERP prova que o sistema de informação é um fator importante no BPO. Inclusive, sua utilização provou reduzir horas de trabalho, como percebido na empresa $\mathrm{B}$ onde as horas de trabalho reduziram $235 \%$ em 2013 e tendem a reduzir mais de 100\% em 2014.

A agilidade foi um fator bastante repetido nas entrevistas, as empresas de médio porte desejam informações o mais breve possível e a falta dela desencadeia no baixo aproveitamento do serviço no âmbito gerencial. Este aspecto foi citado pelos entrevistados E3 e E5, que hoje utilizam informações internas para a tomada de decisões.

Já E4 concorda com o que diz Byrt (2013) sobre o BPO tornar-se complemento da contabilidade da empresa. Compartilhando a ideia de Halvey e Melby (2007) no que diz respeito a reestruturar sua ferramenta junto ao terceirizado, dividindo algumas responsabilidades, mas contando com a gestão terceirizada na área fiscal e de auditoria devido a constantes mudanças e complexidade. Observando este fato, há espaço para o fornecimento de soluções de auditoria contábil e fiscal.

\section{Considerações finais}

O trabalho teve como finalidade analisar as características do BPO contábil e fiscal em empresas de médio porte de Caxias do Sul atendidas pelo mesmo escritório. A pesquisa permitiu afirmar que focar o BPO em médias empresas pode gerar uma vantagem competitiva e econômica aos escritórios de contabilidade. Entre os fatores que definiram a preferência pelo BPO, destacam-se a viabilidade econômica, eficiência operacional, a comunicação entre profissionais e a agilidade dos resultados. Entre os 5 entrevistados, apenas E4 repensa o modelo, todavia seu descontentamento atual é causado por fatores como a falta de integração entre os softwares empresarial e contábil e a carência de escritórios capazes de desenvolver o BPO de forma adequada.

Com o estudo compreendeu-se, também, que nem sempre o custo é o grande fator no momento da opção por um serviço terceirizado pelas empresas de médio porte. Embora tenha sido vantajoso a utilização do BPO contábil e fiscal para a redução de custos em quatro das cinco empresas estudadas. Custo é um dos aspectos, mas não necessariamente tem-se uma redução de custos na terceirização, o que se tem é uma melhor qualidade do serviço pelas equipes multidisciplinares, e liberação da capacidade de gerenciamento da parte contábil, fiscal e de departamento de pessoas. Assim, evidencia-se a vantagem competitiva na utilização do BPO decorrente de outros aspectos alem do custo, pois devido a complexidade atual da contabilidade (ANEFAC, 2013) realizá-la internamente acarretaria em menos qualidade, perda da capacidade gerencial em outras áreas e menor nível de precisão com maior risco.

Sobre os pontos negativos do BPO destacados por Mattos, Dias e Gonçalves (2008), houve alguns apontamentos pelos entrevistados. A inconsistência em algumas informações geradas, e a retirada de documentos da empresa e o custo de demissões.

Além disso, levando em consideração a porcentagem de empresas que ainda analisam o BPO (ANEFAC, 2013), conclui-se que uma melhor comunicação sobre o BPO pode suprir a 
necessidade de informações e credibilidade. Inclusive, identifica-se a oportunidade de investimentos em profissionais capacitados em contabilidade gerencial, escopo que não está sendo aproveitado pelos escritórios contábeis de maneira adequada, aspecto afirmado pelas empresas entrevistadas, que realizam sozinhas ou utilizam-se de outros profissionais para a tomada de decisões.

Por fim, propõe-se aos escritórios contábeis um mapeamento dos clientes, identificando as dimensões preteridas individualmente, para alcançar deste modo a satisfação total do cliente e os resultados desejados.

A pesquisa contribuirá tanto em meio acadêmico, por fornecer informações sobre o BPO contábil e fiscal, quanto para que o empresário contábil que busca diversificação possa compreender aspectos pertinentes do serviço. No meio empresarial esta pesquisa contribuirá para que as empresas tenham informações no que diz respeito aos custos e outros aspectos do BPO contábil e físcal, para que obtenham informações para analisar e utilizar-se do serviço disponível.

Esta pesquisa é limitada por reunir informações em uma amostra de 5 empresas de médio porte localizadas na cidade de Caxias do Sul conjuntamente com informações de produção do escritório contábil prestador para todas elas, centrado na mesma região. As empresas estudadas são: uma do ramo de artefatos de uso doméstico, duas empresas do ramo de autopeças e duas empresas do ramo de vestuário e calçados. Portanto, as conclusões são válidas para este ambiente de pesquisa.

Propõe-se para o futuro, uma pesquisa no âmbito quantitativo, para identificar por ramo de empresa, ou por região, as características do BPO e os aspectos positivos do serviço. Comparar todos os aspectos envolvidos, entre a escolha da contabilidade interna ou terceirizada é considerado um complemento a esta pesquisa. Percebeu-se na pesquisa documental que muitas pequenas e médias empresas não utilizam todo potencial do ERP, sendo assim a análise da implantação deste sistema na empresa por um escritório especializado em BPO e os aspectos desta implantação também se torna uma interessante área de pesquisa.

\section{Referências}

ALVAREZ, M. S. B. Terceirização: parceria e qualidade. 2.ed. Rio de Janeiro: Campus, 1998. ANEFAC, Contabilidade: Solução sob medida. Revista Associação Nacional dos Executivos, Administração e Contabilidade. Disponibilidade: https://www.anefac.com.br/RevistasSumarios.aspx?ID=5600. [20 de outubro de 2013].

BARNEY, J. B; HESTERKY, W. S. Administração estratégica e vantagem competitiva. Tradução Monica Rosemberg. São Paulo: Person Prentice Hall, 2007.

BRUNI, A. L; FAMÁ, R. Gestão de custos e formação de preços. 5. ed. São Paulo: Atlas. 2011.

BYRT, F. Financial Outsourcing Services Seen Growing 8 Percent Annually Through 2017.

Disponibilidade: https:/www.accountingweb.com/article/financial-outsourcing-services-seengrowing-8-percent-annually-through-2017/221538. [09 de outubro de 2013].

CFC (Brasil). Profissionais Ativos nos Conselhos Regionais de Contabilidade agrupados por Gênero. Disponibilidade: $\quad$ https://www3.cfc.org.br/spw/crcs/ConsultaPorRegiao.aspx?Tipo=0 [12-de outubro de 2013]. 
CLICK, R. L.; DUENING, T. N. Business Process Outsourcing: The Competitive Advantage. Hoboken, New Jersey: John Wiley \& Sons, Inc, 2005. Disponibilidade: https://www.csbdu.in/pdf/Business.Process.Outsourcing. The.Competitive.Advantage.2006.pdf . [14 de março de 2014]

ECKERT, A; ROXO, G. G.; MECCA, M. S.; BIASIO, R. Quanto gastam os escritórios de contabilidade para se manterem atualizados sobre a legislação tributária? Estudo \& Debate, v. 22, n. 1, pp. 7-26, 2015.

ELHARIDY, A. M; BRIAN NICHOLSON, B; SCAPENS, R. The embeddedness of accounting outsourcing relationships. Qualitative Research in Accounting \& Management, v.10, n: 1, pp.60 - 77, 2013. DOI: https://dx.doi.org/10.1108/11766091311316194 · [15-de oitombro de 2013].

FABRETTI, L. C. Contabilidade Tributária. 12 ed. São Paulo: Atlas, 2012.

FEE - Fundação de Economia e Estatística do estado do Rio Grande do Sul. PIB dos municípios do RS em 2014: desempenho dos serviços contribuiu com os principais ganhos de participação Disponível em: http://www.fee.rs.gov.br/indicadores/pib-rs/municipal/destaques/ Acesso em: 31 abr. 2017.

FIGUEIREDO, R. M.; BREMER, C. F; MALDONADO, J. Evolução dos modelos de outsourcing: o estado da arte da literatura dos novos provedores de serviços de aplicativos. Perspectivas em Ciência da Informação, Belo Horizonte, v. 8, n. 1, pp.40-57, semestral, 2003.

GIL, A. C. Como elaborar projetos de pesquisa. 4 ed. São Paulo: Atlas, 2007.

Halvey, J. K.; MELBY, B. M. Business Process Outsourcing: Process, Strategies, and Contracts. 2 ed. Hoboken, New Jersey: John Wiley \& Sons, Inc, 2007.

HALF, R. Salary Guide, [Online]. Robert Half. Disponibilidade: https://www.roberthalf.com.br . [07 de junho de 2014].

HERNANDES, A. A nova realidade do BPO contábil e fiscal, [Online]. Disponibilidade: https://www.andersonhernandes.com.br/2010/11/20/1567/. [30 de setembro de 2013].

LACITY, M.C., WILLCOCKS, L.P., 2014. Business process outsourcing and dynamic innovation. Strategic Outsourcing. v.7, n. 1, pp. 66-92

LAKATOS, E. M; MARCONI, M.A. Fundamentos de metodologia científica. 7 ed. São Paulo: Atlas, 2010.

LIMA, C. A. de C. BPO e os departamentos contábil e fiscal, [Online]. Administradores. Disponibilidade: $\quad$ https://www.administradores.com.br/artigos/economia-e-financas/bpo-e-osdepartamentos-contabil-e-fiscal/36146/. [26 de outubro de 2013].

MARCONI, M. de A; LAKATOS, E. M. Técnicas de pesquisa: planejamento e execução de pesquisas, amostragens e técnicas de pesquisa, elaboração, análise e interpretação de dados. 7.ed. São Paulo: Atlas, 2008.

MARTINS, E. Contabilidade de custos. 10 ed. 2 v. São Paulo: Atlas, 2010. 
MATTOS, M. A; DIAS, J. P; GONÇALVES, J. G. Estudo da viabilidade técnica e econômica da terceirização dos serviços contábeis nas indústrias de plásticos em Curitiba. In: $18^{\circ}$ Congresso brasileiro de contabilidade, 24 a 28 de agosto de 2008, Gramado, Rio Grande do Sul. Anais. Disponibilidade: https://www.congressocfc.org.br/hotsite/trabalhos 1/115.pdf. [26 de outubro de 2013].

MORAES, R. P; SARATT, N. D; SILVEIRA, A. D. Empregabilidade na gestão de serviços. Porto Alegre: Badejo, 2003.

PRESIDÊNCIA DA REPÚBLICA, CASA CIVIL. Código Civil. Disponibilidade: https://www.planalto.gov.br/ccivil 03/leis/2002/110406.htm. [10-de março de 2014].

REZENDE, D. A. Planejamento de sistemas de informação e informática: guia prático para planejar a tecnologia da informação integrada ao planejamento estratégico das organizações. 4 ed. São Paulo: Atlas, 2011.

ROCCO, N. Contabilidade: terceirizar ou ter na empresa? [Online]. IG São Paulo. Disponibilidade: https://economia.ig.com.br/financas/seunegocio/contabilidade-terceirizar-ou-terna-empresa/n1237617847429.html. [20 de outubro de 2013].

SCHMIDT, M. Escritório contábil requer diferenciação, [Online]. Jornal do Comércio. Disponibilidade: https://jcrs.uol.com.br/site/noticia.php? $\operatorname{codn}=136542$. [15 de outubro de 2013].

SÎRBU, J; NAGY, A; PINTEA, F. R. The Development of Leadership and Business Process Outsourcing (BPO) Skills. Procedia Economics and Finance, Târgu-mures-Romênia, v. 3, p.1141-1147, outubro de 2012. DOI: 10.1016/S2212-5671(12)00287-0.

STRAUSS, A; CORBIN, J. Basics of Qualitative Research: Techniques and Procedures for Developing Grounded Theory. 2 ed. London: SAGE Publications, 1998.

THOMÉ, I. Empresas de serviços contábeis: estrutura e funcionamento. São Paulo: Atlas, 2001.

TURCI, F; FEITOSA, F. Burocracia: empresas tentam se adaptar a regras que mudam todo dia. [Online]. Jornal Nacional 2013. Disponibilidade: https://g1.globo.com/jornalnacional/noticia/2013/11/burocracia-empresas-tentam-se-adaptar-regras-que-mudam-tododia.html. [03-de março de 2013].

VORA, M. Best Practices in Business Process, [Online] financial executives international. Disponibilidade: $\quad$ https://www.financialexecutives.org/KenticoCMS/Financial-ExecutiveMagazine/2010 06/Outsourcing--June-2010.aspx. [9-de outubro de 2013].

YANG, D; KIM, S; NAM, C; MIN, J. Developing a decision model for business process outsourcing. Computers \& Operations Research, Korea, v. 34, n. 12, pp.3515-3778, dezembro de 2007. DOI: 10.1016/j.cor.2006.01.012. 